\title{
EMBEDDING COMMUNITY-BASED FLOOD RISK MANAGEMENT IN INVESTMENT \\ A PART-TO-WHOLE APPROACH
}

Rabindra P. Osti

NO. 12

December 2017

\author{
ADB EAST ASIA \\ WORKING PAPER SERIES
}


East Asia Working Paper Series

\section{Embedding Community-Based Flood Risk Management in Investment: A Part-to-Whole Approach}

Rabindra P. Osti

No. 12 | December 2017
Rabindra Osti is a water resources specialist at the Asian Development Bank. 
(c) 2017 Asian Development Bank

6 ADB Avenue, Mandaluyong City, 1550 Metro Manila, Philippines

Tel +63 2632 4444; Fax +6326362444

www.adb.org

Some rights reserved. Published in 2017.

Printed in the Philippines.

Publication Stock No. WPS179186-2

DOI: http://dx.doi.org/10.22617/WPS179186-2

The views expressed in this publication are those of the authors and do not necessarily reflect the views and policies of the Asian Development Bank (ADB) or its Board of Governors or the governments they represent.

ADB does not guarantee the accuracy of the data included in this publication and accepts no responsibility for any consequence of their use. The mention of specific companies or products of manufacturers does not imply that they are endorsed or recommended by ADB in preference to others of a similar nature that are not mentioned.

By making any designation of or reference to a particular territory or geographic area, or by using the term "country" in this document, $A D B$ does not intend to make any judgments as to the legal or other status of any territory or area.

This work is available under the Creative Commons Attribution 3.0 IGO license (CC BY 3.0 IGO)

https://creativecommons.org/licenses/by/3.0/igo/. By using the content of this publication, you agree to be bound by the terms of this license. For attribution, translations, adaptations, and permissions, please read the provisions and terms of use at https://www.adb.org/terms-use\#openaccess

This CC license does not apply to non-ADB copyright materials in this publication. If the material is attributed to another source, please contact the copyright owner or publisher of that source for permission to reproduce it. ADB cannot be held liable for any claims that arise as a result of your use of the material.

Please contact pubsmarketing@adb.org if you have questions or comments with respect to content, or if you wish to obtain copyright permission for your intended use that does not fall within these terms, or for permission to use the ADB logo.

Notes:

In this report, "\$” refers to United States dollars.

ADB recognizes "China" as the People's Republic of China.

Corrigenda to ADB publications may be found at http://www.adb.org/publications/corrigenda

The ADB East Asia Working Paper Series is a forum for stimulating discussion and eliciting feedback on ongoing and recently completed research and policy studies undertaken by the East Asia Department of the Asian Development Bank (ADB) staff, consultants, or resource persons. The series deals with key economic and development problems, as well as conceptual, analytical, or methodological issues relating to project/program economic analysis, and statistical data and measurement. The series aims to enhance the knowledge on Asia's development and policy challenges; strengthen analytical rigor and quality of ADB's country partnership strategies, and its subregional and country operations; and improve the quality and availability of statistical data and development indicators for monitoring development effectiveness.

The ADB East Asia Working Paper Series is a quick-disseminating, informal publication whose titles could subsequently be revised for publication as articles in professional journals or chapters in books. The series is maintained by the East Asia Department. 


\section{CONTENTS}

BOX AND FIGURES

ABBREVIATIONS V V V V V V V

ACKNOWLEDGMENTS vi

EXECUTIVE SUMMARY vii

$\begin{array}{ll}\text { I. INTRODUCTION } & 1\end{array}$

II. FLASH FLOOD WARNING SYSTEMS IN THE PEOPLE'S REPUBLIC OF CHINA 3
A. Background
B. Key Features of a Flash Flood Warning System 3
C. Implementation $\quad 5$
D. Operation of Flash Flood Warning Systems 6
E. Observation 6
F. Progress and Outlook $\quad 6$

III. COMMUNITY-BASED FLOOD FORECASTING AND EARLY WARNING:

PILOT PROJECTS IN BENGAWAN SOLO RIVER BASIN, INDONESIA 8
A. Profile of Pilot Villages
8
B. Project Description
C. Lessons Learned

IV. GUIDING PRINCIPLES AND RECOMMENDATIONS FOR COMMUNITY-BASED FLOOD RISK MANAGEMENT

A. Principles $\quad 16$

B. Recommendations and Guidelines 17

$\begin{array}{ll}\text { V. CONCLUSION } & 20\end{array}$ 


\section{BOX AND FIGURES}

\section{BOX}

Elements of Flood Risk Management 2

\section{FIGURES}

1 Information Flowchart for a Flash Flood Warning System 4

2 Schematic of a Flash Flood Warning System in the People's Republic of China 5

3 Development of Hydrometric Station Network in the People's Republic of China 7

4 Community-Based Flood Forecasting and Early Warning System Established in Pilot Communities

5 Sample Data Gathered from the Automatic Rain-Gauge Station in Pajeng-Bengawan Solo and the Automatic Warning Message Issued

6 Elements of an Effective Flood Forecasting and Early Warning System 


\section{ABBREVIATIONS}

$\begin{array}{ll}\text { ADB } & \text { - Asian Development Bank } \\ \text { BBWS-BS } & \text { - Bengawan Solo River Basin Agency } \\ \text { BPBD } & \text { - Regional Disaster Management Agency of Indonesia } \\ \text { BSRB } & - \text { Bengawan Solo River Basin } \\ \text { CBFRM } & - \text { community-based flood risk management } \\ \text { FFWS } & \text { - flash flood warning system } \\ \text { FRM } & - \text { flood risk management } \\ \text { PRC } & - \text { People's Republic of China } \\ \text { PusAir } & - \text { Research and Development Center for Water Resources under Indonesia's Ministry of } \\ & \text { Public Works and Housing } \\ \text { SMS } & - \text { short message service } \\ \text { SOP } & - \text { standard operating procedure }\end{array}$




\section{ACKNOWLEDGMENTS}

The author, Rabindra P. Osti, would like to thank the East Asia Department (EARD) of the Asian Development Bank (ADB), particularly Qingfeng Zhang, director of EARD's Environment, Natural Resources and Agriculture Division (EAER), for his supervision and inspiration; and Indu Bhushan, director general, EARD, for his endorsement of this publication.

The valuable support of ADB's Sustainable Development and Climate Change Department (SDCC) is also highly appreciated-notably to Gil-Hong Kim, senior director concurrently chief sector officer, Sector Advisory Service Cluster. Special thanks likewise go to the SDCC's Knowledge Sharing and Services Center (SDCC-KS) and Climate Change and Disaster Risk Management Division (SDCD) for the funding support of this publication.

This knowledge product has benefitted from the significant contribution of the following ADB peer reviewers: Eric Quincieu, senior water resources specialist (water sector group), Environment, Natural Resources and Agriculture Division, Southeast Asia Department, Indonesia Resident Mission; Arghya Sinha Roy, senior disaster risk management specialist (climate change adaptation), SDCD; and Charles Rodgers, consultant (climate change and disaster risk management), SDCD.

Xiaotao Cheng, professor at the China Institute of Water Resources and Hydropower Research, and John William Porter, senior water resources engineer and former ADB consultant, updated relevant data and information, reviewed the final draft, and offered insightful comments and suggestions. Akiko Terada-Hagiwara, principal economist, Office of the Director General, EARD, provided overall guidance during the production of this publication.

Joy Quitazol-Gonzalez facilitated the production process from initial reviews, revisions, formatting, proofreading, engagement of service providers, and through to final publication. The author also acknowledges the assistance of Heidee Luna and Mary Dianne Rose Molina, EAER; Sophia Castillo-Plaza, EARD; and Ellen Pascua, SDCC. 


\section{EXECUTIVE SUMMARY}

According to the World Disasters Report (2016) by the International Federation of Red Cross and Red Crescent Societies, floods, together with storms, accounted for $76 \%$ of natural hazards occurrence globally and caused 87\% of economic damages by natural disasters from 2006 to 2015, with 62\% of damages sustained in Asia.

To help flood-prone communities manage flood hazards as well as minimize their exposure and reduce their vulnerability to these hazards, flood risk management measures need to be put in place. The concept of community-based flood risk management (CBFRM) as a pragmatic and holistic approach to flood management at the grassroots level has therefore evolved. Such approach recognizes the importance of enhancing community responsibility and ownership in the development process, particularly in the areas of project planning, design, and implementation. However, CBFRM has not yet been considered as a stand-alone development practice nor seriously and systematically applied in the field.

Community-based approaches have been used in different contexts of development projects. In this paper, case studies of pilot community-based practices in flood risk management in the People's Republic of China and Indonesia are reviewed, and the lessons learned serve as practical guidelines. These basic guiding principles form the backbone of the CBFRM process and are relevant in developing arrangements for investment projects: (i) community organization, (ii) financing, (iii) capacity development, (iv) gender and social inclusion, (v) risk management, (vi) technology transfer, and (vii) cultural norms and values.

Embedding community-based approaches, particularly in flood risk management investment programs, can help enhance community resiliency, increase ownership and participation by the beneficiaries, maximize the benefits of investment, and improve the sustainability of benefits. 



\section{INTRODUCTION}

Flash floods and landslides are common natural occurrences for many countries in Asia and the Pacific. In recent years, extreme weather events such as intense storms and severe typhoons have been increasing in frequency and magnitude as a result of climate variability. In July 2017, for example, continuous heavy rainfall led to severe flooding in much of the southern region of the People's Republic of China (PRC), causing some Yangtze River tributaries to overflow. More than 14.9 million people in 11 southern and central provinces were affected. ${ }^{1}$ Hardest hit was the city of Changsha, capital of Hunan Province, where over 960,000 residents were evacuated. ${ }^{2}$ Landslides in Sichuan Province in June and August of the same year killed more than 100 people. In August 2017, monsoon floods reached record high levels in the South Asian countries of Bangladesh, India, and Nepal, affecting more than 16 million people and claiming over 400 lives. This was one of the most destructive floods in recent years, inundating one-third of Bangladesh and many parts of Nepal, India, and Pakistan. ${ }^{3}$

In the PRC, flooding is historically common in the southern and central regions during the wet season months of June to September. In 2016, following a strong El Niño event, the monsoon rainfall (which commenced in mid-June) was well above average, causing massive flooding, particularly in the middle and lower parts of the Yangtze River Basin. The 2016 summer floods affected 20 provinces in the PRC, damaged 7.2 million hectares of crops, destroyed 410,000 homes, and killed over 900 people. ${ }^{4}$ The estimated total damages reached $\$ 38$ billion (CNY256 billion) (footnote 4). According to the international disasters database Emergency Events Database (EM-DAT), this represents the second largest economic loss from floods in the PRC's history, and is the world's fifth most expensive non-US weather-related disaster ever. ${ }^{5}$ The majority of the casualties were associated with landslide and flash flood disasters, and much of the damages were incurred in small- to moderate-sized river basins.

Flood hazards can translate into disasters that substantially disrupt the livelihood of people and cause losses and damages exceeding the capacity of the community to cope on their own. ${ }^{6}$ If not managed properly, flood disasters can wipe out hard-won development gains, trapping those affected in a cycle of poverty from which it can be very difficult to escape. This applies particularly in floodplains, which are among the most populated and densely developed areas in the world. According to the World Disasters Report 2016, from 2006 to 2015, floods, together with storms, accounted for 76\% of natural hazards globally and caused $87 \%$ of economic damage by natural disasters. ${ }^{7}$ During the same period, Asia accounted for $62 \%$ of global economic damages due to flood disasters.

1 China News. 2017. National Defense: Affected population from 2017 floods has exceeded 14.9 million. 29 June. http://news. china.com.cn/live/2017-06/29/content_38441975.htm (in Chinese) or http://www.top-news.top/news-13050638.html.

2 Xinhua News Agency. 2017. 964,600 residents relocated in Central China's Hunan due to flood. 4 July. http://news.xinhuanet. com/english/2017-07/04/c_136416590.htm.

3 Al Jazeera Media Network. 2017. Floods affect 16 million in Nepal, India and Bangladesh. 18 August. http://www.aljazeera.com/ news/2017/08/floods-affect-16-million-nepal-india-bangladesh-170818084524219.html.

4 Aon Benfield. 2016. Natural Catastrophe Report for China in Summer 2016. October. http://thoughtleadership.aonbenfield. com/Documents/201610-china-summer-floods.pdf.

5 EM-DAT. http://www.emdat.be/ (Accessed 25 August 2017).

6 United Nations International Strategy for Disaster Reduction (UNISDR). 2009. Terminology on Disaster Risk Reduction. http://www.unisdr.org/we/inform/terminology.

7 International Federation of Red Cross and Red Crescent Societies. 2016. World Disasters Report 2016-Resilience: Saving Lives Today, Investing for Tomorrow. Geneva, Switzerland. 


\section{Box: Elements of Flood Risk Management}

Flood risk management embraces a range of measures that address three key elements: (i) managing flood hazard, (ii) minimizing exposure to flood hazard, and (iii) reducing the vulnerability of people and property exposed.

Managing flood hazard involves modifying physical characteristics of floods, either by river infrastructure works, or by catchment management measures such as controls over forestry and agricultural practices.

Managing exposure to floods involves measures such as property acquisition, land use zoning, building codes, planning development controls, and elevated building.

Managing flood vulnerability involves nonstructural measures, such as community awareness, flood forecasting and warning, preparedness, emergency response, and post-flood early recovery strategies.

The flood risk management process allows these measures to be weighed against physical, social, and economic conditions; and addresses specific issues that characterize each river basin.

Source: Y. Kobayashi and J. W. Porter. 2012. Flood Risk Management in the People's Republic of China: Learning to Live with Flood Risk. Manila: Asian Development Bank. https://www.adb.org/publications/flood-risk-management-peoples-republic-china-learninglive-flood-risk.

Flood risk management-which includes identification and reduction of flood risk as well as management of residual risk through improved preparedness-has long been discussed, advocated, and practiced (Box). Although flood-prone communities are the most vulnerable to disasters, they are often not very aware of the benefits flood risk management measures can provide. This leads to missed opportunities to sustain their livelihoods and strengthen their resiliency, and to protect lives and property during emergencies.

The concept of community-based flood risk management (CBFRM) has evolved as a holistic approach to enhance community responsibility and engagement in the development process. Self-help, mutual-help, and public-help scenarios are essential elements in responding to flood disasters. ${ }^{8}$ Whereas self-help and mutual-help among local residents are most useful in providing prompt emergency response, especially when affected sites are rendered inaccessible (due to disruption of transport and communications, for example), the public-help element (provided mainly by government) is essential in sustaining benefits for affected communities in the long term.

CBFRM is consistent with contemporary principles of integrated water resources management, integrated river basin management, integrated flood risk management, and disaster risk management. However, CBFRM has not yet been considered as an essential development practice nor found widespread application in the field. Community participation is generally limited to community consultations to secure community acceptance of project implementation, depriving communities of the full benefits of a CBFRM approach. A more systematic approach that recognizes the importance for communities to participate in project planning, design, and implementation is needed so that outcomes are better suited to their special needs.

8 Cabinet Office. 2015. Learning from the Mega-Tsunami Disaster. The Second Expert Group Meeting on the Great East Japan Earthquake. Government of Japan, Tokyo; and Sendai City Government. 2016. Tackling Community Disaster Prevention through Self-Help, Mutual Aid, and Public Assistance. http://sendai-resilience.jp/en/efforts/sendai/. 
Broadly viewed as a pragmatic and holistic approach to flood management, different forms of CBFRM have been tried in several countries. This paper presents case studies of community-based pilot projects in the PRC and in Indonesia, synthesizes lessons learned from these pilots, and proposes easy-to-use guidelines for embedding CBFRM into investment programs. Knowledge shared on good practices in this paper likewise complements the ongoing country water assessment initiative of the Asian Development Bank (ADB) in the PRC, which highlights community empowerment as one of its recommendations for water-related disaster risk management.

\section{FLASH FLOOD WARNING SYSTEMS IN THE PEOPLE'S REPUBLIC OF CHINA}

\section{A. Background}

Flash floods, including debris flows and landslides caused by heavy downpour of rain, are a serious problem in the PRC. Casualties caused by floods have declined substantially elsewhere in the PRC since 1949, but remained high in mountainous areas where the risk from flash floods was more difficult to manage. By the first decade of the current century, more than $75 \%$ of all deaths attributable to floods occurred in mountainous regions and were due to these types of natural disasters. In 2010 alone, flash floods were responsible for well over 3,800 deaths or missing people. ${ }^{9}$ Aware of this outstanding problem in national flood management, the Government of the PRC formulated a framework for managing flash flood risk in 2003 and, in 2006, approved the implementation of pilot projects in 103 counties. Based on the lessons learned from these pilot studies, over 2,000 flash flood warning systems (FFWSs) have since been implemented nationwide.

The Chinese FFWS approach represents an alternative approach, and one from which lessons may be learned about how governments and communities can effectively work together to manage flood risk. The FFWS approach relies heavily on nonstructural measures, and involves raising community awareness of flood risk and assisting affected communities to prepare for and respond appropriately to flash flood emergencies. Although it is more of a centralized approach as compared to other forms of CBFRM practices, there is genuine engagement of communities in preparing for and responding to floods. Community members participate to supplement efforts by government agencies and government officials in the processes of monitoring conditions, disseminating warnings, and evacuating to places of safe refuge.

\section{B. Key Features of a Flash Flood Warning System}

The model framework for an FFWS in the PRC is implemented at county level. It includes eight key features or steps, as discussed briefly below.

(i) Conduct preliminary research and investigations to identify and map main hazard zones and places for safe refuge.

(ii) Determine appropriate threshold values (of rainfall or water levels) that signify imminent hazard. The threshold values are used to trigger warnings and may be revised or refined in light of subsequent experience.

9 D. Sun, D. Zhang, and X. Cheng. 2012. Framework for National Non-Structural Measures for Flash Flood Prevention in China. Water. 4 (1). pp. 272-282. 
(iii) Plan a suitable monitoring network, and select appropriate monitoring and warning equipment. Components of existing hydrometeorological networks may be integrated into the monitoring network of the FFWS. Typically, a network will include automatic recording (telemetered) gauges, plus manual gauges that can be observed by community members and data relayed by mobile phone via the global system for mobile communications network.

(iv) Equip the county with necessary facilities.

(v) Develop a central warning platform using computer hardware and software including database, geographic information system, forecasting models, electronic maps, etc.

(vi) Organize a five-level hierarchy of responsibility and accountability-at county, town, village, production group, and household levels. Assign duties and channels of communications, with inbuilt redundancy in case any component fails or is missing.

(vii) Document a preparedness plan that includes, among others, actions to be taken during alerts and emergencies. It may also include small-scale structural measures to protect communities.

(viii) Undertake training to raise risk awareness, and inform all levels how the system works and the provisions of the preparedness plan. Perform trial exercises and field drills. Disseminate information to all levels of the hierarchy as appropriate.

State Flood Control and Drought Relief Headquarters are the project management agencies that supervise implementation and operation of FFWSs, and have produced a series of guideline documents that specify requirements and minimum standards. Figure 1 shows the conceptual information flowchart from the guidelines.

Figure 2 illustrates the structure of a typical FFWS. Systems include links to share information with other tiers of government and between multiple government departments at each level.

Figure 1: Information Flowchart for a Flash Flood Warning System

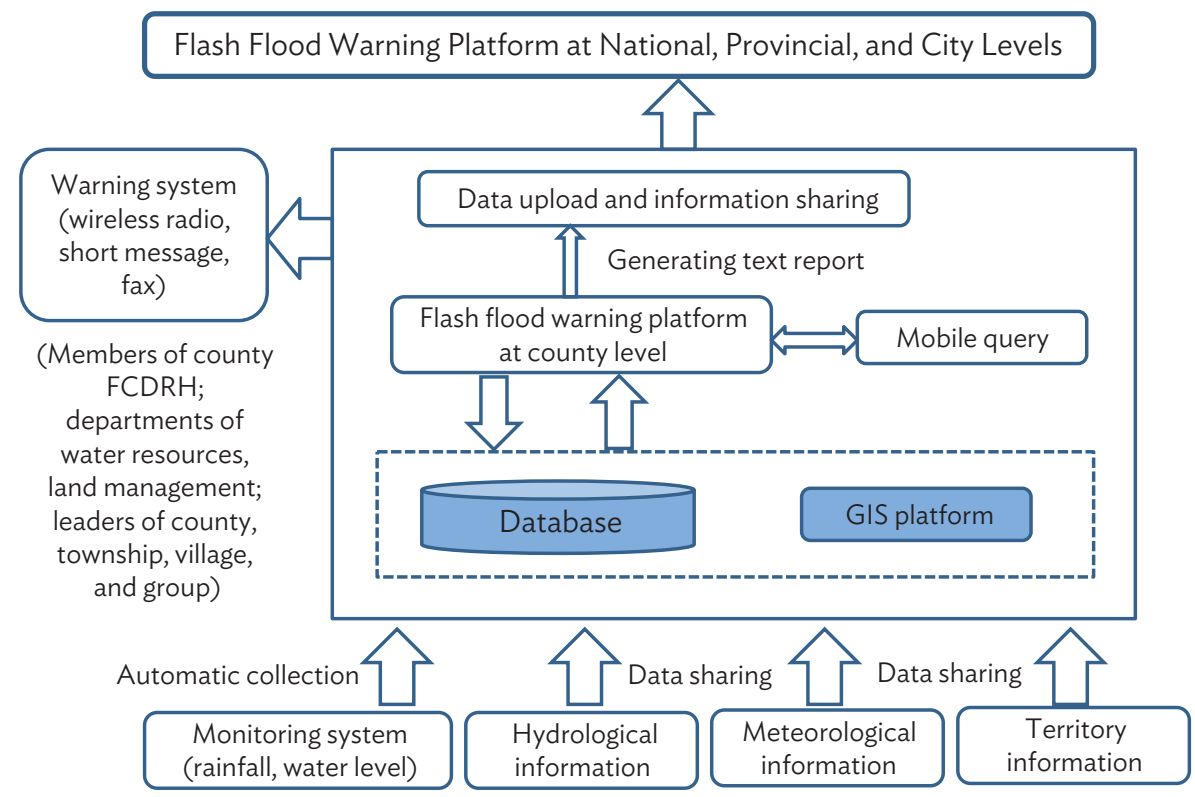

FCDRH = flood control and drought relief headquarter, GIS = geographic information system. Source: China Institute of Water Resources and Hydropower Research (IWHR), Ministry of Water Resources of the People's Republic of China. 


\section{Figure 2: Schematic of a Flash Flood Warning System in the People's Republic of China}

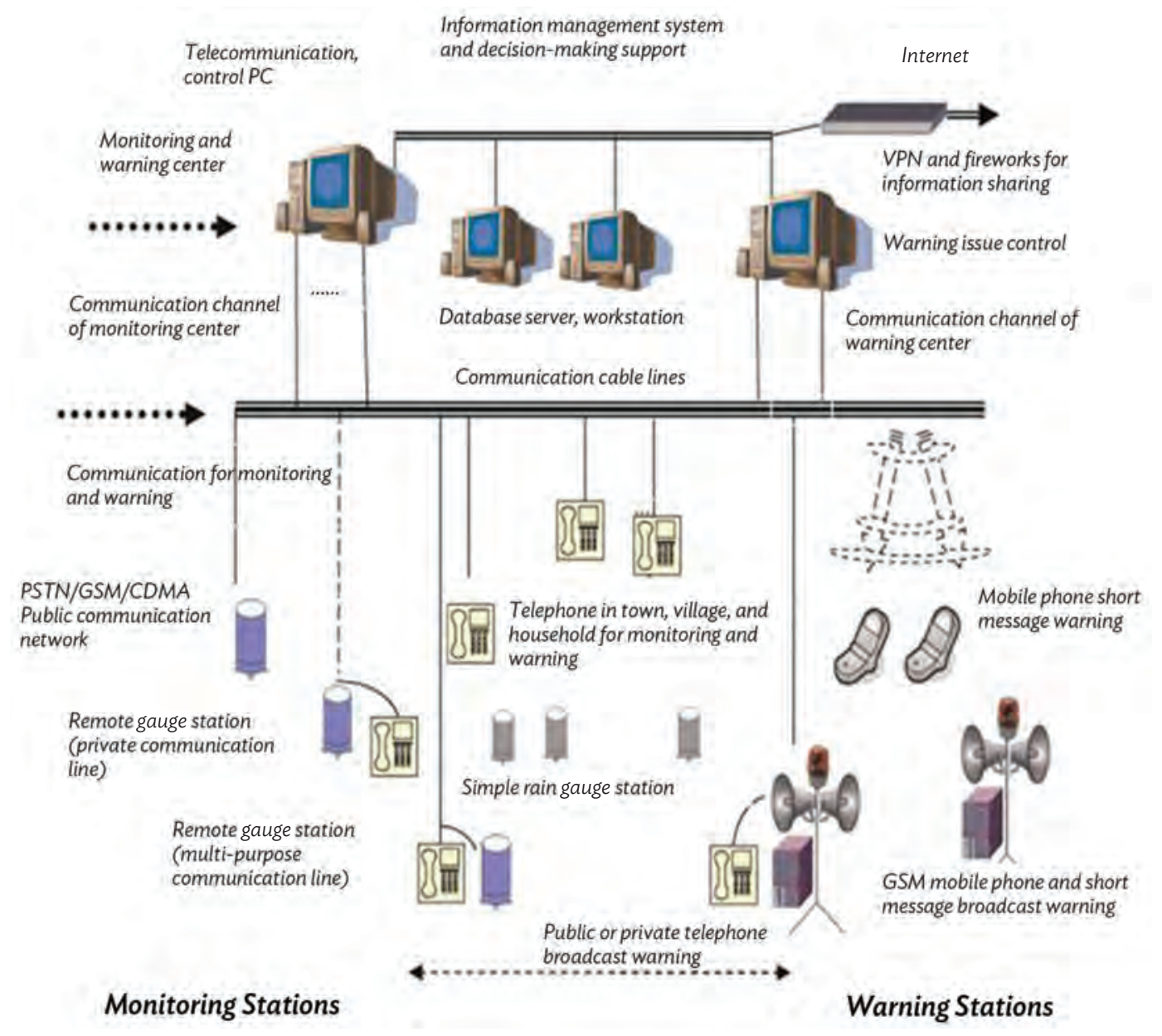

CDMA = code-division multiple access, GSM = global system for mobile communication, $\mathrm{PC}=$ personal computer, $\mathrm{PSTN}=$ public switched telephone network, VPN = virtual private network.

Source: Jianming Ma, Xuming Tan, and Nianqiang Zhang. 2010. Flood Management and Flood Warning System in China. Irrigation and Drainage. 59 (1). pp. 17-22.

\section{Implementation}

The central government of the PRC has invested heavily in FFWSs and, as noted above, more than 2,000 had been implemented in counties all across the nation by 2016, and the program is continuing to add new systems every year. The FFWS framework was initially developed by national research institutions to suit conditions in the PRC, before being endorsed at executive level by the State Council in 2006. Consistent with a common development paradigm in the PRC, the new initiative was first required to be trialed in pilot projects in advance of a national rollout of the systems. By 2009, pilot projects were implemented in 103 selected counties prior to expansion of the program. During the pilot program, lessons were learned regarding practical details of implementing and operating the systems, but the model framework described above remained essentially unchanged.

Because it is a national system and has been methodically planned, there is much uniformity about FFWSs that have been implemented; they are invariably implemented at county scale, and with only 
minor variations necessary to adapt to specific local conditions. For example, although the model FFWS relies principally on nonstructural flood management measures, where appropriate, communities may be supported to design and implement small-scale structural measures to mitigate flood hazard as a component of their county systems for flash flood risk management. Recognizing that centralized flood forecasting cannot extensively penetrate the PRC's grassroots communities, development of more stand-alone flash flood early warning systems in towns situated in small-sized river sub-basins is also required.

\section{Operation of Flash Flood Warning Systems}

The central warning platform continually polls automatic gauging stations in the monitoring network, populates its database, and shares data with external agencies. When it recognizes that a threshold value has been exceeded, warnings are issued. Delegated officials receive text messages to alert them to the danger and prompt them to take necessary action. Warnings may also be sent directly to installations that trigger devices such as sirens, flashing lights, etc. Voice messages may also be automatically broadcast over loud speaker systems. Officials mobilize operatives at each level of the hierarchy, leading to actions on appropriate preventive measures and evacuation of residents to places of safe refuge.

Sun et al. (2012) attest to a case study of an FFWS completed in Shennongjia on the border between Sichuan and Hubei provinces (footnote 10). A newly implemented system triggered warnings during a major storm that occurred in August 2011 with record overnight rainfall of 270 millimeters. In response, more than 28,000 families were safely evacuated without a single life lost.

A similar but locally calibrated, stand-alone, and real-time rainfall-threshold-based flood early warning system is planned for development with technical assistance from ADB. Upon approval of the technical assistance project, the pilot system will be developed for the isolated communities in small-sized river sub-basins (mainly in areas in the Yangtze River basin hit by the 2016 floods), with strong participation of the local communities.

\section{E. Observation}

As may be appreciated from the description above, the success of the system depends on a high level of social organization. Its sustainability will also depend on continuity of active support by local governments, ongoing maintenance and updating of equipment, and periodic renewal of awarenessraising, training and practice exercises. In the PRC, strong mechanisms for accountability and social organization are in its favor; however, the problem of alert fatigue will be a challenge in the medium and longer term. The system may not be directly translatable into all other societies, but is worthy of serious study to consider how it may be adaptable. In any case, it represents one of the most concerted efforts anywhere in the world to tackle the special problems that flash floods present.

\section{F. Progress and Outlook}

Real-time river observation system. In 2012, the PRC invested an estimated $\$ 7.02$ million for a real-time river observation project covering five provinces and some major tributaries of the major rivers. ${ }^{10}$ The project had two major components: (i) flash flood early warning systems and (ii) small river hydrologic

10 WaterWorld. 2012. Flash flood early warning, forecasting systems to help five Chinese provinces better manage water resources. http://www.waterworld.com/articles/2012/04/flash-flood-early-warning-systems-in-china.html. 
monitoring systems. Flash flood monitoring and forecasting systems established in Heilongjiang, Fujian, and Guizhou provinces consisted of data collection and early warning modules and a platform for information dissemination; whereas, the small river hydrological monitoring systems implemented in Anhui and Shanxi provinces involved the establishment of automatic collection and transmission systems for rainfall and water level data.

Monitoring of hydrological, engineering and disaster information of the seven major rivers and other key flood control areas in real time is important because it improves the accuracy of flood (and drought) forecasting, helps establish a stand-alone early warning system for isolated areas, and thus provides scientific basis and technical support for water resources management and decision making, including flood risk management. In addition, real-time river observation system will support the application of the new river chief system, which is currently being implemented nationwide. Aimed at promoting better coordination and integration of water resources management, the river chief system requires officials at every level of government to take full responsibility for the protection of rivers and lakes in regions under their jurisdiction.

Flood forecasting and early warning systems. The shift towards a more integrated flood management approach from the traditional, fragmented, and localized approach has highlighted the importance of flood forecasting and warning, thereby prompting the PRC to build up its hydrological forecasting technology and capacity. By the end of 2013, the Ministry of Water Resources has been maintaining over 86,500 hydrometric stations, which include 4,195 hydrological stations, 9,330 water-level stations, and 43,028 rain-gauge stations (Figure 3). ${ }^{11}$

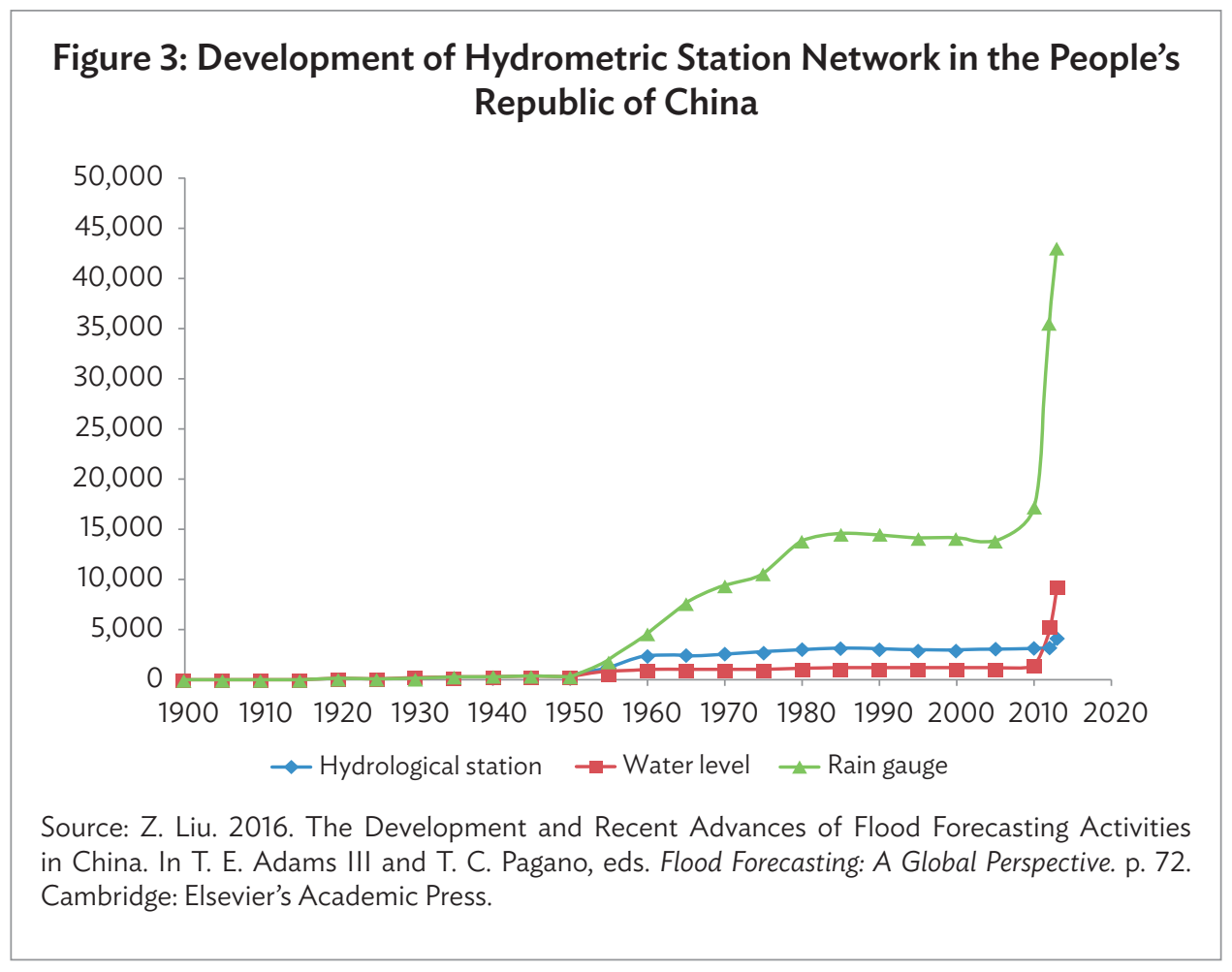

11 Z. Liu. 2016. The Development and Recent Advances of Flood Forecasting Activities in China. In T. E. Adams III and T. C. Pagano, eds. Flood Forecasting: A Global Perspective. pp. 67-86. Cambridge: Elsevier's Academic Press. http://dx.doi. org/10.1016/B978-0-12-801884-2.00003-7. 
To support flood prevention in small- to medium-sized rivers and in mountainous regions, the PRC is working on further developing large-scale flood forecast and early warning systems in these areas. In the alpine areas of the Xinjiang Uyghur Autonomous Region, for example, the government worked closely with the United Nations Development Programme to improve flood surveillance and forecasting, enhance snowmelt flood control and prevention systems, and build snow-melting floods emergency management capacity. ${ }^{12}$ In 2012, the project established an alpine weather station and two hydrological monitoring stations; it also ensured the timely provision of data through the development of remote sensing acquisition and processing systems.

This and other similar projects have enhanced the capacities of local governments and communities to promptly prepare and respond to flood risks in order to prevent human and economic losses. The PRC continues to invest and develop new technologies and utilize innovative tools to improve flood forecasting and early warning needed for the grassroots communities.

\section{COMMUNITY-BASED FLOOD FORECASTING AND EARLY WARNING: PILOT PROJECTS IN BENGAWAN SOLO RIVER BASIN, INDONESIA}

A community-based flood forecasting and early warning project was implemented in 2010 and 2011 in the villages of Kedung Sumber and Semen Pinggir in Bojonegoro district, East Java, Indonesia. ${ }^{13}$ This project was funded by ADB and implemented by the International Center for Water Hazard and Risk Management.

\section{A. Profile of Pilot Villages}

The Kedung Sumber village is about 10 kilometers $(\mathrm{km})$ from the Bojonegoro district capital, situated on the bank of the Pacal River, a small sub-basin (only 14 square kilometers in area) of the large Bengawan Solo River Basin (BSRB). This mountainous community of 200 households is exposed to flash floods, and is usually flooded within half an hour of intense rainfall. The village is situated on a fertile alluvial fan, which is critical to the livelihoods of the local farmers. The area around the village is highly susceptible to landslides, making it difficult to relocate it to a safer location. This is typical of a large number of rural villages in Indonesia. In 2011 alone, this village suffered nine flood events. In each, inundation depths exceeded one meter, and the community suffered significant physical damage. Kedung Sumber village is listed by the Regional Disaster Management Agency (BPBD) as the most vulnerable community in the BSRB, citing flash flood as the major problem. Emergency response in villages like Kedung Sumber is very challenging because of the difficult terrain, poor access, and poor communications due to weak and unreliable phone signals.

The Semen Pinggir village, with 200 households, lies at the confluence of the Pacal River and the Bengawan Solo River (about $25 \mathrm{~km}$ aerial distance north from Kedung Sumber village), and is within the suburban area of Bojonegoro City. In this community, floods may occur due to overtopping, either of

\footnotetext{
12 United Nations Development Programme in China. Research on Modelling for Flood Forecasting in Alpine Areas in Western China and its Demonstration Project. http://www.cn.undp.org/content/china/en/home/operations/projects/environment_ and_energy/research-on-modelling-for-flood-forecasting-in-alpine-areas-in-w.html.

13 Technical assistance was provided by ADB to help Bengawan Solo River Basin Authority pilot the community-based flood forecasting and early warning system. (ADB. 2016. Supporting Investments in Water-Related Disaster Management. Technical Assistance Partner's Report. Manila [TA 7276-REG].)
} 
the Bengawan Solo River or of the Pacal River, or from both due to the backwater in the Pacal River when water levels in both Pacal and Bengawan Solo rivers rise simultaneously.

These types of flood are frequent in Indonesia but often neglected since (i) little is known or understood about their spatial distribution; (ii) they occur in a multitude of small towns and villages all through Indonesia; (iii) real-time data acquisition and its use for forecasting are quite difficult; and (iv) limited available resources render post-disaster field collection of data, including estimation of damages, inadequate.

\section{B. Project Description}

The following activities were conducted in these pilot communities jointly with the BPBD, the Bengawan Solo River Basin Agency (BBWS-BS), and other local government agencies including the district water resources agency.

\section{Stage 1. Awareness Raising}

Flood risk management experts, civil volunteer groups, nongovernment organizations, and community facilitators were mobilized to gather information on damages, analyze the risk situation, raise public awareness, encourage community members to participate, and facilitate the preparation of communitybased flood hazard, exposure and risk mapping. Community members viewed different items, including video clips of historical events and best practices from around the world. Public and individual consultations and flood games, including role plays, were conducted during village meetings involving vulnerable groups such as the disabled, children, women, and the elderly. This stage helped underscore the importance of flood risk management.

\section{Stage 2. Community Mobilization}

In the village meetings, community members agreed to formulate a standard operating procedure (SOP) for flood risk management, and established a special committee, with subcommittees to serve different purposes-e.g., data interpretation, safety provision, evacuation, logistics for relief works, and first aid. Members of the special committee were selected through consensus, and the themes of subcommittees were based on needs and past experience of committee members. Although members had experience in dealing with flood disasters in the past, they were not confident about where to evacuate; when to evacuate, because floods develop very rapidly; how to evacuate; whose instructions should be followed; how to save their cattle and their valuable assets, etc. The project helped mobilize the communities and enabled individuals to share their views, common issues, and individual problems, and explore solutions through public consultation and a formalized decision-making process.

\section{Stage 3. Community-Based Vulnerability Assessments}

Participatory Rural Appraisal tools were applied to help community members assess their vulnerability with respect to the typology of floods. Different scenarios of flooding were simulated by experts and shared with community members for ground-truthing purposes. The community conducted the discussion, which led to the updating or revision of the flood maps, identification of their exposure and vulnerability, and, most importantly, setting of priorities to improve key sectors that are vulnerable to flood disaster. These sectors include, but are not limited to, agriculture, small enterprises, education, health, and commerce. Community-based flood hazard, exposure, and emergency evacuation maps were finalized. Flood hazard and evacuation maps were revised and posted in several public places for quick and emergency reference, according to community consensus. 


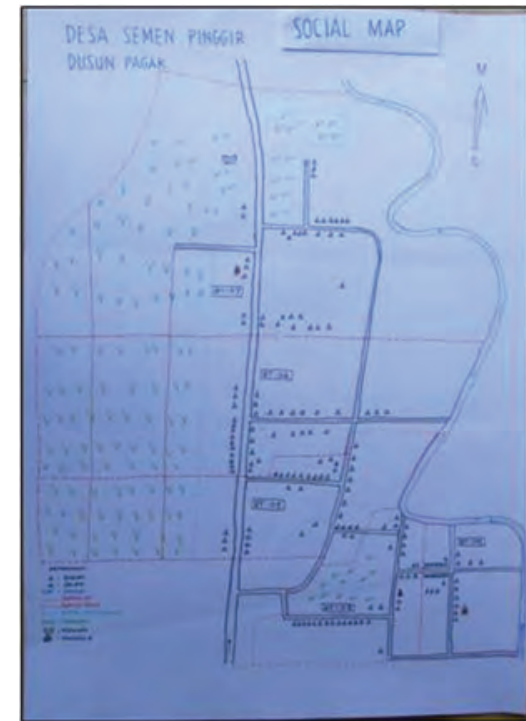

Social Map

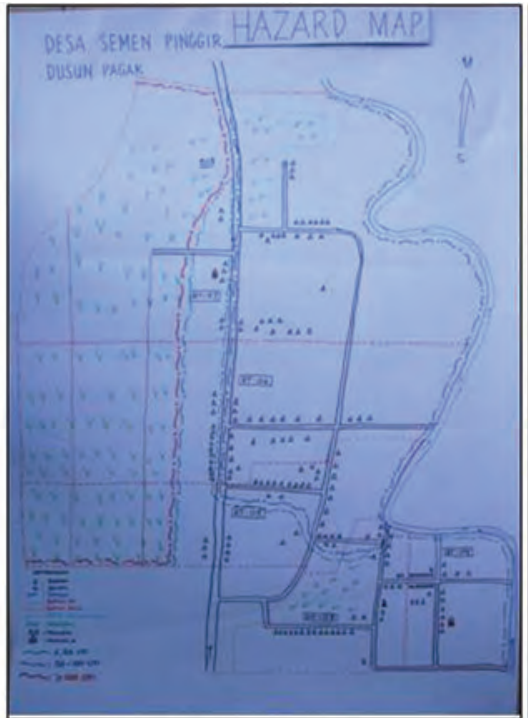

Hazard Map

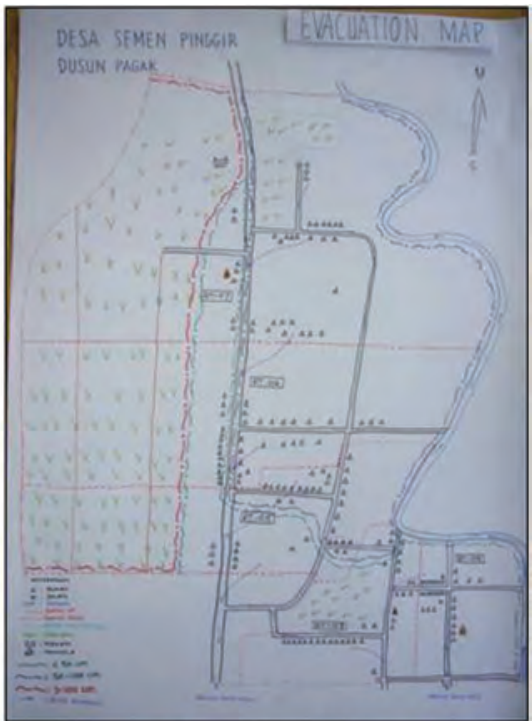

Evacuation Map

Community-drawn risk, hazard, and response maps in Semen Pinggir village, Bojonegoro, Indonesia. Flood mapping is a crucial element of flood risk management (photo by the Asian Development Bank).

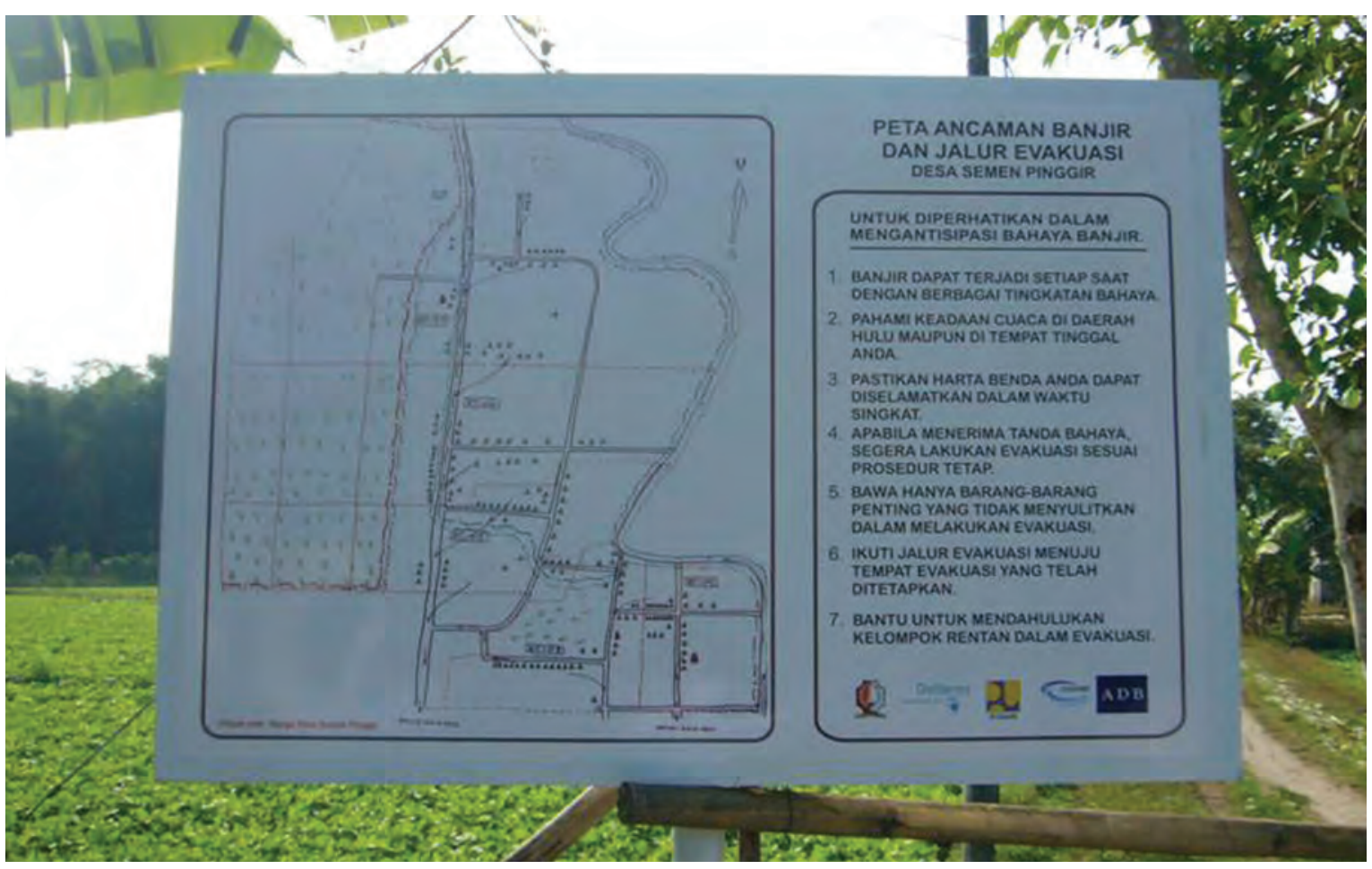

Community-based emergency response map in Semen Pinggir village, Bojonegoro, Indonesia. Flood maps and their regulatory information are posted in public places for easy reference during emergencies (photo by the Asian Development Bank). 


\section{Stage 4. Community-Based Early Warning System}

It was technically difficult to connect the communities to the national flood forecasting and early warning system for various reasons: (i) the Pacal River basin is a small sub-basin with very short available lead time for flood forecasting and early warning; (ii) the basin was not gauged for rainfall nor for water level; and (iii) the Kedung Sumber community was not connected to the national telecommunications grid, and both landline and cellphone services were poor due to its remoteness and rugged terrain. The project installed a stand-alone automated rainfall observation device (telemetric rain-gauge station) in Pajeng village, about $7 \mathrm{~km}$ upstream from the Kedung Sumber village, and the device was connected to the local network to provide information to the Kedung Sumber community about rainfall and impending flash flood. The rain gauge was subsequently connected to the BBWS-BS hydrological data network by registering the Internet Protocol of the instrument with the central server and transmitting data to the central data server via the global system for mobile communications network on a regular basis (originally set frequency was 5 minutes). The server can be accessed by the National Board for Disaster Management (BNPB) and the river basin authority, BBWS-BS. The public can view real-time and historical data from the station on the Tech4Water website. ${ }^{14}$ The device can send an alert to villagers in both villages (Figure 4) when rainfall exceeds a predetermined threshold (moving average of 20 millimeters per 30 minutes). The threshold was based on results of hydrological modelling incorporating local conditions that was calibrated using historical flood observations. This provides

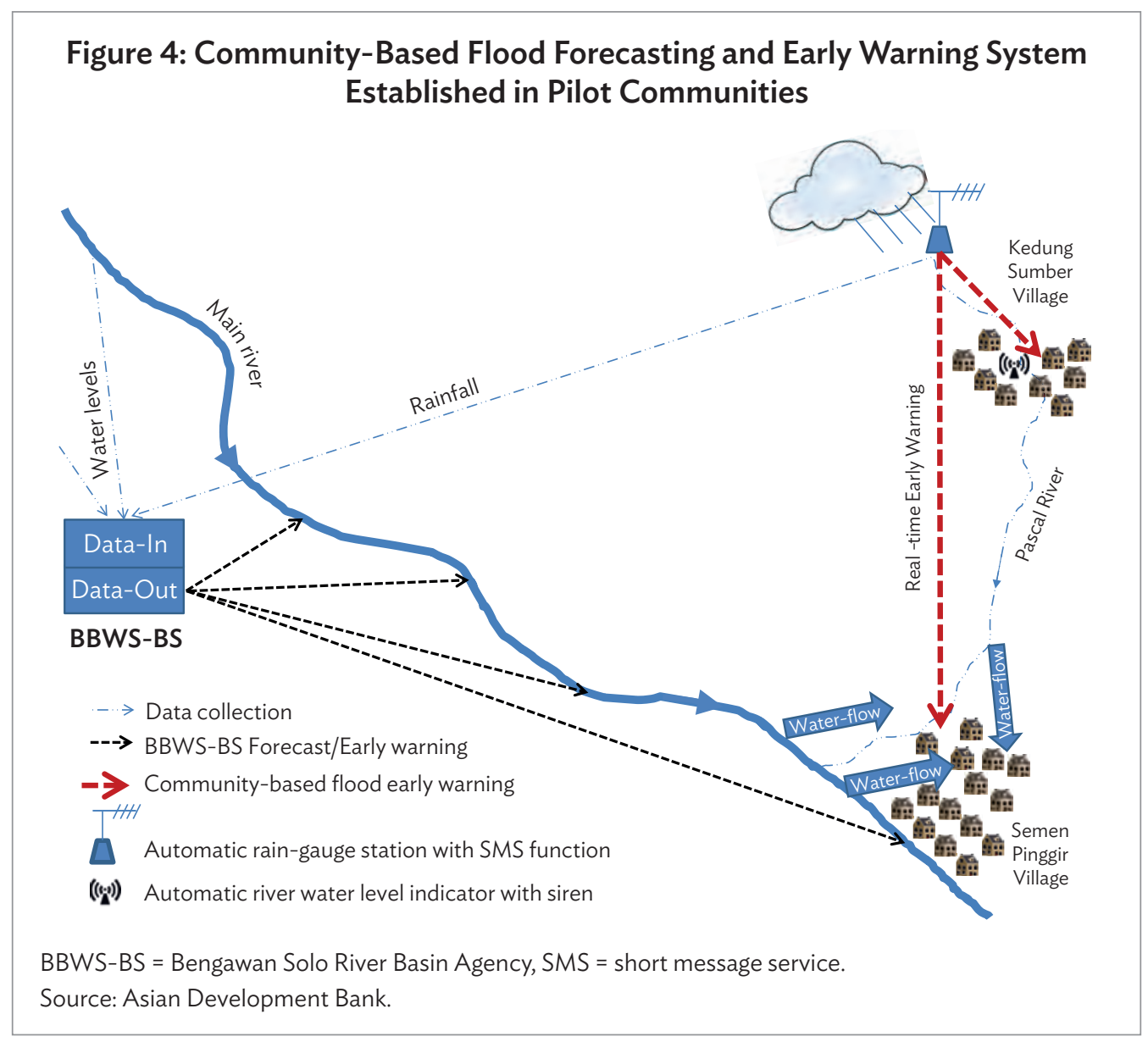

14 Tech4Water. http://www.tech4water.com/?ffws=show\&id=156. 
people of Kedung Sumber around 20 to 30 minutes to prepare and evacuate. The water gauge station next to the village also provides a final warning of bank overflow for last-minute emergency action.

As per the community SOP, a few designated members of the special committee receive alerts and warning messages directly from the rain gauge, and are responsible for disseminating warnings to the community using loud speakers installed in the village mosque. The SOP, together with the warning announcement, also triggers the mobilization of volunteers to support evacuations, with priorities given to those least able to help themselves. With the extended advance warning made possible by the rainfall observation system, people can better save their lives and their most valuable possessions. Together with the BSRB basinwide flood warning system, the rainfall observation at Pajeng also provides vital information and early warning to the Semen Pinggir community, about $30 \mathrm{~km}$ downstream (aerial distance) from the Pajeng station.

\section{Stage 5. The Drill}

In both communities, the special committees conducted evacuation drills with the active participation of the local people. Official certificates of appreciation were given to special committee members by the local authority. The certificate states that the holder has gone through training for flood emergency response and is eligible to take a designated role. It was mandatory for the special committee members to join the drills. Important lessons were learned from the drills that were useful in revising the SOPmajor shortcomings were identified, and limitations and problems were documented. The BPBD and other local authorities, including the police department, witnessed and participated in all activities. The authorities can then make use of these experiences to conduct similar training in other communities.

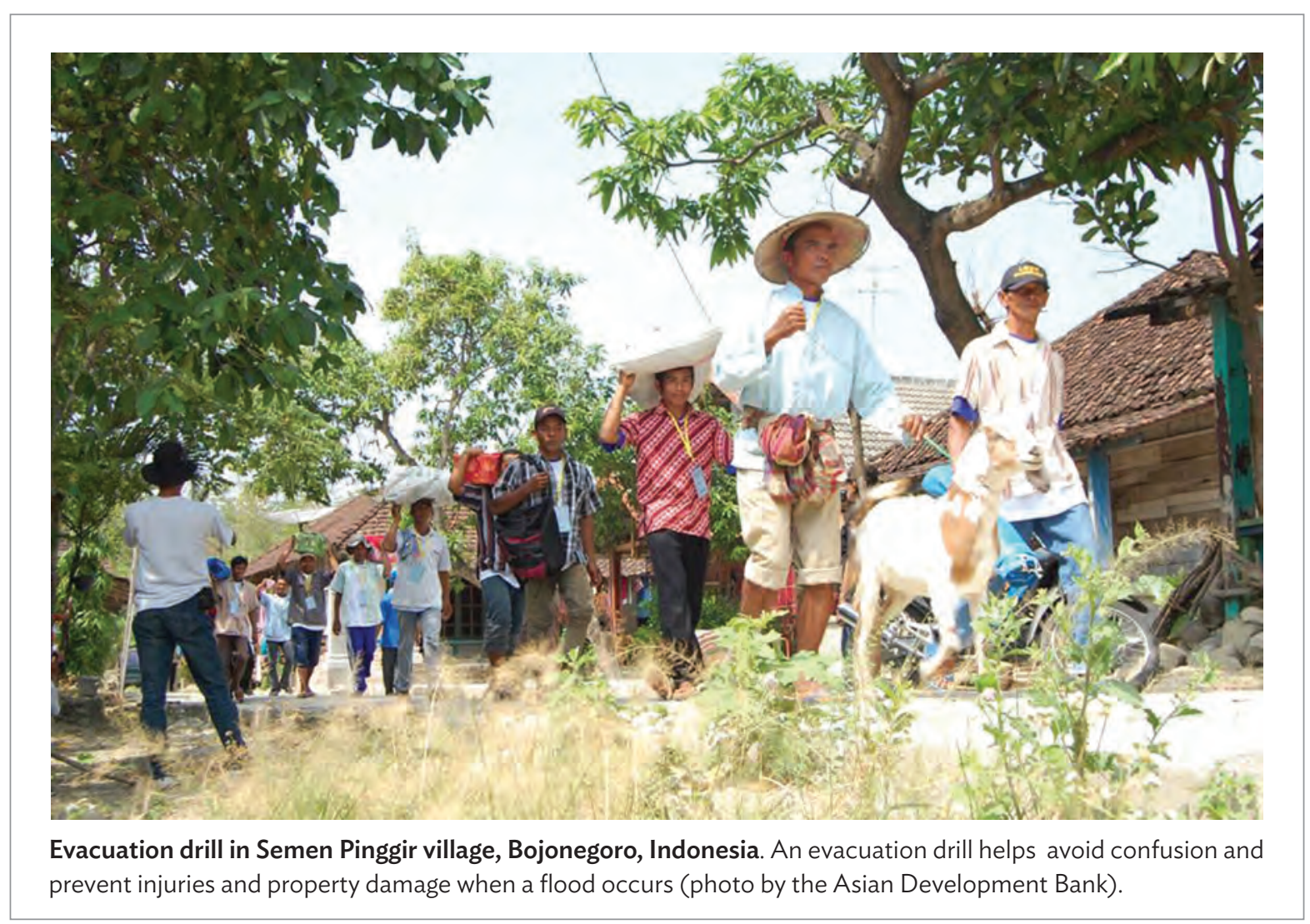




\section{Lessons Learned}

Community flood hazard and exposure maps, as well as adoption and implementation of SOP, are the basis for community-based flood risk management (CBFRM) in the pilot communities. These products are used by the community in everyday practice. The rainfall-based automatic flood warning system installed in Kedung Sumber village on the Pacal River has also proven its effectiveness in early warning.

\section{Confidence of the Community in the System}

On 17 January 2012 at 5:00 p.m., the Kedung Sumber village was flooded. This was one of the worst floods that year in this community. The automated rain gauge sent a text message via the short message service (SMS) to the village leaders showing excess rainfall in the upstream area at around 4:10 p.m. Thirty minutes later, the flood level in the river adjacent to the village reached the first level of warning. At 4:50 p.m., the flood level reached the second level of warning; and, at 5:00 p.m. overbank flow

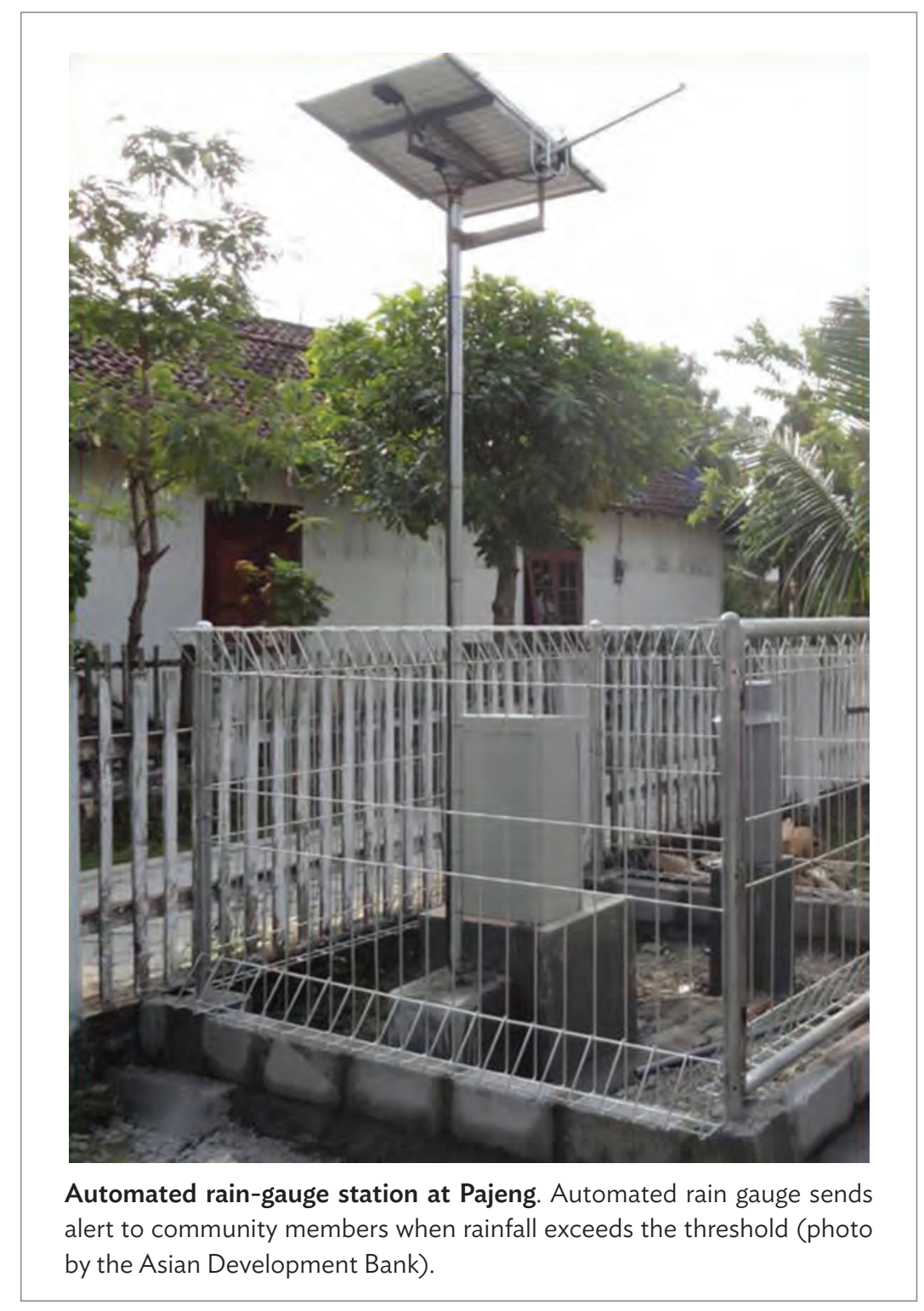


commenced and inundated the village. In this case, the rain gauge station provided an extra 30 minutes lead-time in flood warning, which is quite critical for saving lives and property. However, the community members, including village leaders, were not confident in the warning message because several had been issued previously during system calibration and commissioning. Moreover, the extreme storm rainfall in the upstream area was not evident to the community, just like in past flood events. By the time they acted, it was too late for the community to realize the severity of the event and save valuable assets. On the other hand, the authorities in Bojonegoro City received the same auto-message from the rain gauge station, and were able to reach the village to extend their support within 2 hours.

The lesson learned from the January 2012 event helped boost the confidence communities had in the system. It was very helpful in saving lives and property during a worse flood that occurred on 4 December 2012 in the same village. At 5:40 p.m. that day, the automatic rainfall device at Pajeng recorded 50.5 millimeters of rain in 30 minutes. The system sent a warning SMS alert to the village leaders at Kedung Sumber village and local authorities, including BPBD Bojonegoro district. The message was also received at the Research and Development Center for Water Resources (PusAir) under the Ministry of Public Works and Housing in Bandung. The content of the text message was: "Flash flood danger alert! Save your valuable goods, and evacuate immediately." (Figure 5 contains data and warning message from the Pajeng-Bengawan Solo station). This time, as per the SOP, village leaders informed the villagers

Figure 5: Sample Data Gathered from the Automatic Rain-Gauge Station in Pajeng-Bengawan Solo and the Automatic Warning Message Issued

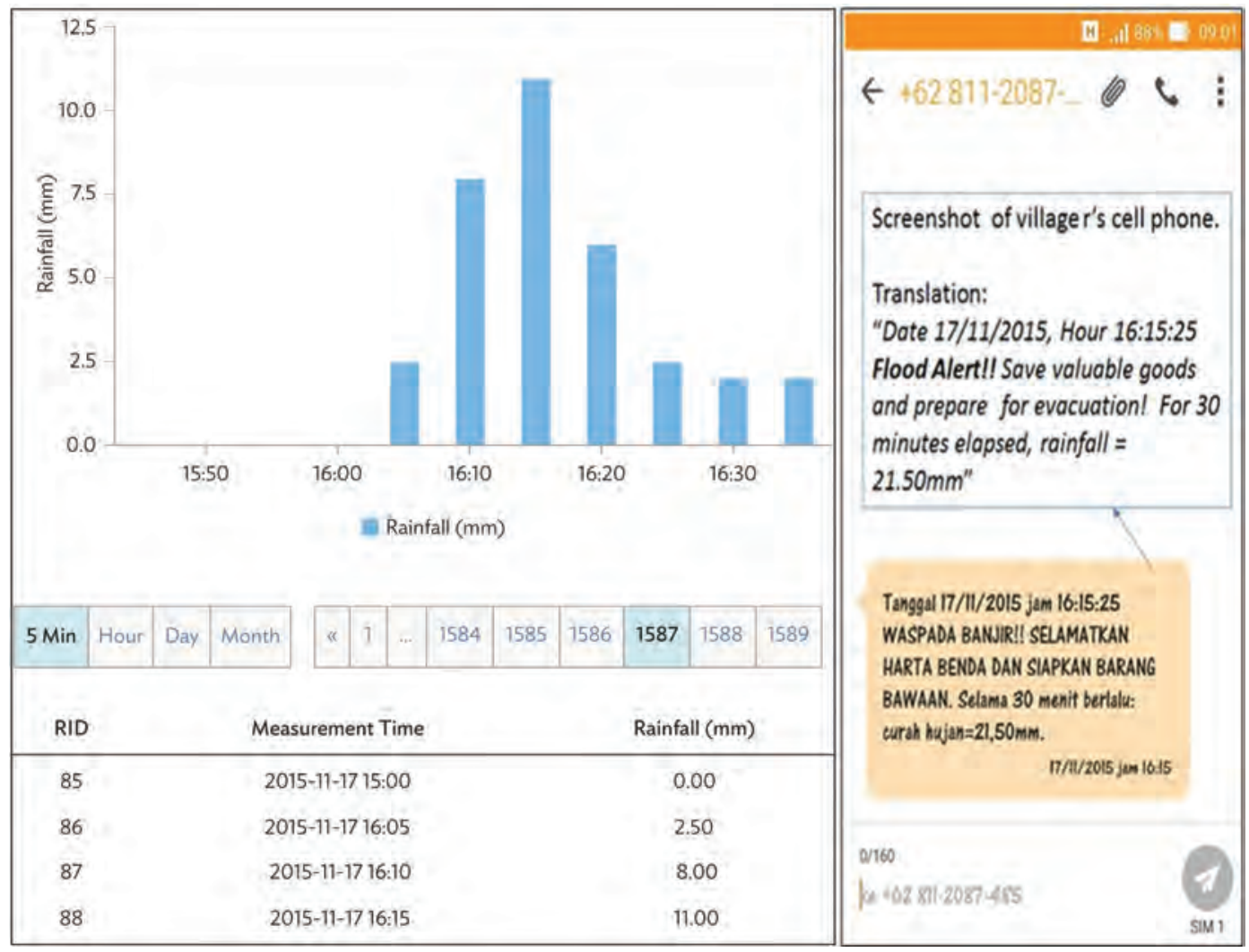

$\mathrm{mm}=$ millimeter, $\mathrm{RID}=$ reference identification.

Source: Research and Development Center for Water Resources (PusAir). 
utilizing the loud speaker facility of the nearby mosque. As a result, villagers started evacuation to higher places, mostly in neighbors' houses in flood-free zones designated by the hazard map. As the rainfall continued and intensity increased in the upstream area, the system sent more messages to the villages on a regular basis with the indication of increasing severity and higher warning levels. Although sandbags and embankments at several locations were damaged, a few houses were destroyed, and walls of many houses collapsed, there was no human casualty.

The timeline of incidents as recorded by the village leader is shown below.
5:40 p.m. Received SMS alert/warning from the system.
6:00 p.m. People with infants or disabilities began evacuation first to houses on higher ground, followed by others, some with belongings.
6:30 p.m. River overflow commenced.
7:00 p.m. Flood depths reached 60 centimeters to 100 centimeters in most areas; high velocity of flood water observed inside the village, so people were unable to cross the stream of water.

9:00 p.m. Floodwater began to recede; Vice-Regent and BPBD Bojonegoro arrived for inspection.

In addition to its flash flood early warning function, the rain gauge station has continuously provided hourly rainfall data to the Tech4Water system established at PusAir in Bandung. Together with rainfall data from other stations in the Solo River Basin, hydrological data from the Tech4Water server have been utilized for flood forecasting in the Solo River main stream corridor, and for development planning in the river basin.

\section{Maintenance of the System}

Local residents who provide security for the station at Pajeng are trained in operation and maintenance of the rain gauge, and are paid a modest stipend for their services. However, technical issues, like programming and hardware functions, are still critical issues for long-term sustainability of the system. The system also requires continued calibration for higher accuracy of warning messages. Such technical support can only be provided by a specialized agency. An agreement between the central government and PusAir was signed, which allowed PusAir to operate and maintain the system over 3 years, together with ongoing calibration of the rainfall threshold for early warning in the form of a research and training program. After 3 years of operation, the responsibility was transferred to the Directorate General of Water Resources (and mainly to the river basin authority BBWS-BS), under the Ministry of Public Works and Housing.

Since its installation, the rain gauge station has been functioning properly and, to date, continues to provide real-time data which are available to the public through the Tech4Water website (footnote 15). These data are being recorded and updated every 5 minutes. For wider dissemination of data and timely provision of early warning messages to the public and relevant authorities, the river basin authority has been utilizing the text messaging service or SMS of a local network provider for a minimal fee. In future, the authority may need to consider switching from the current manual payment mode to an automatic recharge system to ensure a continuous and reliable network service. 
In both pilot communities, members meet regularly, share their experiences from past events, and discuss possible amendments in the SOP. Communities have regularly updated maps, adopted several preparedness measures including raising plinth level of new houses, and maintained physical infrastructure, including a flood control levee. During the rainy months, community members prepare emergency sand bags, discuss emergency response, conduct drills, and prepare logistics, including checking communication with upstream and downstream communities. Local authorities are usually invited to take part in evacuation drills.

\section{GUIDING PRINCIPLES AND RECOMMENDATIONS FOR COMMUNITY-BASED FLOOD RISK MANAGEMENT}

\section{A. Principles}

Based on the United Nations International Strategy for Disaster Reduction and its Platform for the Promotion of Early Warning, the following key principles for an effective community-based, peoplecentered early warning system are espoused: ${ }^{15}$

(i) Risk Knowledge. This refers to systematic data collection and risk assessment. (Are the hazards and vulnerabilities familiar? What are the patterns and trends in these factors? Are risk maps publicly accessible and data readily available?)

(ii) Monitoring and Warning Service. This pertains to the development of hazard monitoring and early warning services. (Are the parameters being monitored correct? Does the forecasting method used have sound scientific basis? Can the service generate accurate and prompt warnings?)

(iii) Dissemination and Communication. This refers to the transmission of risk information and early warnings. (Do warnings timely reach those vulnerable and at risk? Are the risks and warnings clearly communicated and understood? Is the warning information accurate and useable?)

(iv) Response Capability. This pertains to the building of community and regional response capabilities. (Are response plans tested and up-to-date? Are local knowledge and capacities sufficient and duly made use of? Are people well-equipped and ready to quickly act on warnings?)

Empowering all those at risk (i.e., individuals and communities threatened by hazards) to act in an appropriate and timely manner to minimize, if not prevent, loss of life, injuries and property damage is the goal of community-based early warning system. These key inter-related principles also need to be supported by two important elements-(i) accurate and sound forecasting and warning, and (ii) reliable information - to make the early warning system complete and effective. Weakness in any of these principles and elements or breakdown in their links and communication channels can result in system failure. Moreover, the following critical cross-cutting issues need to be considered as well: effective governance and institutional arrangements, a multi-hazard approach to early warning, importance of cultural diversity and gender views, and local community participation (Figure 6).

Note that these key principles apply to early warning systems in general, and not specifically to CBFRM.

15 UNISDR. 2006. Developing Early Warning Systems: A Checklist. Third International Conference on Early Warning. Bonn, Germany. 27-29 March. http://www.unisdr.org/we/inform/publications/608. 


\section{Figure 6: Elements of an Effective Flood Forecasting and Early Warning System}

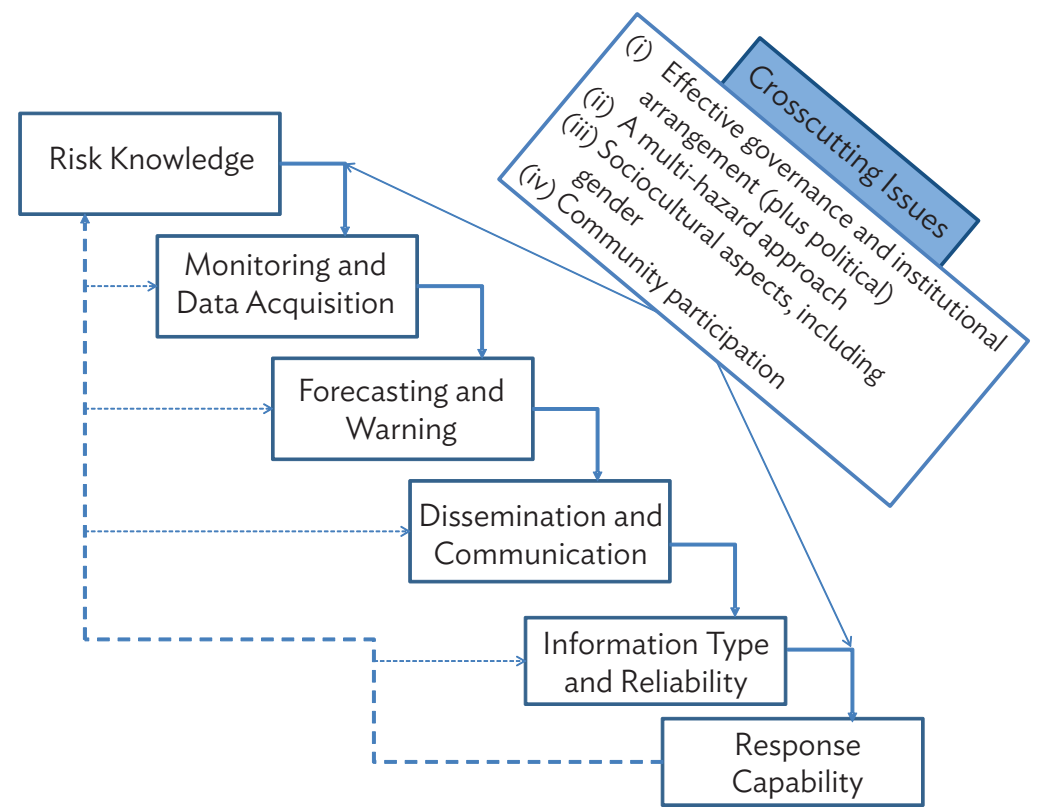

Source: United Nations International Strategy for Disaster Reduction. Platform for the Promotion of Early Warning. http://www.unisdr.org/2006/ ppew/; with modifications by the Asian Development Bank.

\section{B. Recommendations and Guidelines}

From the specific lessons learned and experiences of the pilot communities on flood forecasting and early warning, the following basic guidelines for community-based development in general, and CBFRM implementation in particular, have been formulated. These seven basic guidelines form the backbone of the CBFRM process, and are thus relevant in developing arrangements for investment projects. Depending on the characteristics of communities, it may take some time to gain maturity in the process of community mobilization, for which the role of community facilitators (who best understand local culture and context) is critical.

\section{Community Organization}

Communities need to be organized to be as inclusive as possible. Ideally, community members are all encouraged to be constructively involved in consultations and discussions. For most purposes, groups organized for consultation or discussion should not be too large. Relatively small groups encourage more active engagement and provide greater opportunity for all views to be freely expressed. For example, in a community of 100 households, about five groups should be organized, each comprising about 20 households - and preferably composed of households with common interests and similar levels of flood risk. From each of these organized groups, a representative (or representatives) will be appointed to a special committee on flood risk management (FRM) - or committee on any other matter of concern, as needed. Observers should be invited from relevant line agencies and local government to join special 
committee meetings. If a community organization already exists to serve some other certain purpose, that organization could be used as platform for the establishment of a special committee on FRM.

The special committee should conduct meetings on a regular basis to: (i) discuss prevailing challenges of flooding in the community; (ii) review the progress of any ongoing CBFRM activities; (iii) review their emergency response arrangements, action plans, etc.; (iv) form functional task forces or subcommittees to share roles and responsibilities among members; (v) review their flood risk map; and (vi) plan and conduct emergency drills. The scope of the special committee's meeting should be FRM-related. Whenever appropriate, in the interests of social inclusion and consensus, matters should be referred by the special committee back to the organized community groups for their consideration and discussion. The scope of the community groups' meetings can be broader than just FRM, but should include discussion on proposals submitted by the special committee. Some representatives from the special committee may also participate in local government development committees to provide community input and support in government planning and programming.

\section{2. $\quad$ Financing}

Some capital is usually needed to start up community activities (e.g., programs to raise awareness and preparedness, evacuation measures and drills, flood warning, contingency or emergency response plans, etc.) that reduce vulnerability and improve flood protection at both household and community levels. Capital can usually be raised by community organizations through mobilization of both internal and external resources. Record-keeping on public expenses should be done by a designated committee or subcommittee, and publicly disclosed during meetings of special committees. Funds may be raised within communities for activities relevant to flood protection or climate change adaptation. Community-based savings and microcredit schemes have proven to be an appropriate mechanism to meet the financial needs, particularly to fund small-scale household or community-driven flood mitigation activities. For example, small premiums can be collected on a regular basis to finance a community fund from which loans can be made for mitigation, adaptation, or income generation purposes. Note that if it was necessary to access services of financial institutions such as banks or credit societies, those responsible for fund management may need to form a legal entity.

\section{Capacity Development}

To initiate CBFRM, communities should adequately understand the risks to which they are exposed. To help communities understand the risk they face, formal and informal education should be promoted, including campaigns to raise awareness, participatory learning, appropriate mitigation measures, regular drills, and other initiatives (such as community-based risk mapping); or even formal curriculum-based school education. Communities should learn basic skills and, therefore, may need training programs on a periodic basis. Three key areas are: (i) skills to run organizations, including decision-making and administrative formalities; (ii) technical skills in flood preparedness, emergency response, and risk reduction (e.g., rain gauge observation, correlation between rainfall and flood levels, hazard mapping, plotting inundation depths against discharge or river level, risk assessment, evacuation procedures, structural improvements, etc.); and (iii) skills for vulnerability reduction and coupling flood risk measures with other adaptation measures that may generate income and maintain or enhance livelihoods. National or local governments should assist in assessment of needs, and help organize required training and follow-up programs in close coordination with the special committees. 


\section{Gender and Social Inclusion}

Gender balance in development has proven to have great benefits. It is crucial to support and empower subgroups who are particularly vulnerable to floods. These subgroups include, but may not be limited to, women, children, disabled and elderly persons, minorities, and those in specific occupations such as fishermen or farmers. It is essential to ensure these subgroups actively participate in decisionmaking, and that their concerns are reflected in action plans. Some examples of gender-focused and socially-inclusive activities are (i) special provision of emergency accommodation for women and children in evacuation centers, (ii) adequate access to evacuation centers for disabled persons, (iii) provision of targeted warnings for fishermen or farmers, and (iv) priorities during reconstruction or rehabilitation. A gender-based and socially-inclusive approach is essential to achieve the goal of safer and resilient communities.

\section{Risk Management}

Communities should includevarious management measures to modify hazard, exposure, and vulnerability, using both structural and nonstructural measures. They should provide constructive inputs to relevant authorities in planning and implementing plans at river basin scale, including flood risk plans and environmental management projects. The community-based action plan should complement the goals and objectives of government plans and infrastructure projects, as it helps leverage project benefits to the beneficiaries. Given that different communities have different vulnerabilities and resilience, government activities should be linked to each community's own action plan and contingency plan. When required to plan, design, and implement small-scale projects, a community may need external support. In some developing member countries, for example, it may be possible to mobilize supplementary labor from neighboring villagers or farmers to implement community-driven development activities using traditional labor exchange agreements. Local government should always provide backup to support community initiatives and activities, monitor and evaluate emerging issues, and mainstream appropriate measures into the regional development plans, including the regional flood management plan. Community-based early warning systems can be integrated with basin-scale early warning systems to achieve improved outcomes in emergency response.

\section{Technology Transfer}

Technology transfer relates to the identification of appropriate and effective risk assessment and mitigation tools for community application that suit the local needs and culture. This includes the promotion of local knowledge supported by science and technology. This should be linked to provision of training to develop technical skills under the capacity development component of CBFRM above. Relevant technologies and tools include, but are not limited to, the following: (i) establishment of hydrometeorological rainfall and/or water level gauges that can be observed by the community and linked to real-time forecasting; (ii) development of tools and techniques to assess hazards and estimate risk, e.g., simple correlation curves between rainfall and flood levels; (iii) establishment of an operational community-based early warning system; (iv) adoption of flood-resistant housing and construction techniques; ( $v$ ) river level monitoring; and (vi) promotion of communication tools that facilitate the early warning system, including mobile phone applications, remote sensing, internet links, etc. 


\section{Cultural Norms and Values}

Understanding local culture and its attitudes and values towards space, place, and nature is important in determining appropriate approaches, measures, and actions under CBFRM. For its success, CBFRM interventions should help to effectively bridge or overcome cultural differences whenever they constitute barriers to vulnerability reduction, and form building blocks toward vulnerability reduction based on positive attitudes and consistency with cultural norms. Interventions should respect and not disturb or harm existing traditions and culture that might otherwise lead to social instability or conflict; yet they should also be able to help raise awareness about conventional practices that could exacerbate risks to certain subgroups within the communities.

\section{CONCLUSION}

In many large-scale water and flood infrastructure investment programs, community-based development activities are often disregarded as elements of project safeguard requirements. In other words, the direct engagement of local communities in project design and implementation is sometimes overlooked. The sustainability of large-flood infrastructure projects, such as dikes or dams, can usually be greatly enhanced by the active participation of community members in smaller-scale activities, e.g., improved agricultural practices, pollution control, monitoring of infrastructure, watershed conservation including soil erosion control measures, solid waste management, maintenance of river training works, etc. Involving communities through CBFRM will also energize upstream and downstream linkages and ameliorate potential water rights and water-sharing issues. This type of community engagement facilitates the longterm sustainability of infrastructure projects. Inclusion of CBFRM programs in every investment program will help bridge development gaps by producing more sustainable project outcomes.

Often, engineering-oriented or highly technical agencies are reluctant to incorporate CBFRM into project design for various reasons. Examples include: (i) they may not want to consider social dimensions that could alter their project design; (ii) the process of CBFRM may delay the project preparation and implementation; (iii) low-cost options may be of lower priority in larger infrastructure investment portfolios; (iv) there is no clear mandate or conflicting mandates exist to support these activities; (v) extra effort and resources are needed for CBFRM coordination; or (vi) there is no institutional capacity to adopt CBFRM. If this is the case, there may be a need for enabling the environment, particularly through policy adjustment and building and broadening capacity within institutions, and by facilitating better coordination among relevant agencies. Civil society and nongovernment organizations can play a vital role in establishing CBFRM; however, their capacity may also need to be assessed and empowered. Admittedly, these things may be difficult to achieve, but the endeavor should be rewarded by improved project outcomes and sustainability.

Besides social mobilization, the community may also need empowerment through technical advice and assistance from concerned authorities, particularly in engineering design of small community-initiated civil works such as check dams, solid waste management initiatives, wastewater management measures including sanitation; and in raising community awareness and preparedness, provision of early warning facilities, etc. Depending on its governance system, the implementation arrangements and funding mechanisms may vary from one country to another. CBFRM should be very different from business-asusual with respect to safeguard requirements. Community participation must not be limited to public consultation and advice of project intent. CBFRM not only contributes to sustainability through raising 
awareness, ownership, and responsibility, it also bridges the gap between community needs and project implementation by facilitating robust community engagement with project proponents and participation in a joint decision-making process.

A large investment gap in flood risk management is evident. While there is progress in river flood management, there is still much left to be desired in countries at risk, especially in terms of managing flash floods. In the PRC, for example, the centralized approach of flood risk management had been very effective in the past, particularly in mitigating floods in the main river corridors. But recent flash flood events in small sub-basins become unpredictable and more damaging, as confirmed during the 2016 Yangtze River floods. Therefore, as a holistic approach to flood risk management, a more balanced strategy, which combines both centralized and community-based approaches, is desirable such that not only the technical expertise and organized resources of responsible government agencies can be brought to bear on improved flood management, but also the energies and interests of the communities affected can be activated and engaged to maximize positive outcomes for project beneficiaries. Such an approach is particularly important where there are communities exposed to flash flood hazard, where time available to mobilize official resources in response to an emergency is severely limited, and where communities can be organized and empowered to initiate early action themselves. That requires a degree of self-help and self-organization that is best achieved through CBFRM.

Future investments in community-based development activities (similar to the flood forecasting and early warning systems discussed in this paper) would be beneficial to those countries affected by reducing loss of life, and helping to break the cycle of poverty in which the most vulnerable communities are entrapped. It is therefore recommended that in preparation for future ADB flood management investments, integration of CBFRM should be routinely considered as a means for achieving better social outcomes. It should be recognized as complementary to other social safeguards that are integral to ADB policy. 


\section{Embedding Community-Based Flood Risk Management in Investment A Part-to-Whole Approach}

Flash floods and landslides are common in Asia and the Pacific. In July 2017, continuous heavy rainfall led to severe flooding in much of the southern region of the People's Republic of China (PRC), affecting more than 14.9 million people in 11 provinces. Community-based schemes have evolved into holistic approaches to managing flood risk, which need to be embedded in investment programs. This paper looks at case studies of pilot practices in community-based flood risk management (CBFRM) in the PRC and in Indonesia. It also presents lessons and practical guidelines in developing CBFRM investment projects, particularly highlighting community organization, financing, capacity development, gender and social inclusion, risk management, technology transfer, and cultural norms and values.

\section{About the Asian Development Bank}

ADB's vision is an Asia and Pacific region free of poverty. Its mission is to help its developing member countries reduce poverty and improve the quality of life of their people. Despite the region's many successes, it remains home to a large share of the world's poor. ADB is committed to reducing poverty through inclusive economic growth, environmentally sustainable growth, and regional integration.

Based in Manila, ADB is owned by 67 members, including 48 from the region. Its main instruments for helping its developing member countries are policy dialogue, loans, equity investments, guarantees, grants, and technical assistance. 